\title{
Growth Hormone Secretagogue Peptide-6 Modulates Antimicrobial Activities in Tilapia (Oreochromis sp.) Challenged with Edwardsiella tarda
}

\author{
Liz Hernández ${ }^{1}$, Hanlet Camacho ${ }^{2}$, Adriana Nuñez-Robainas ${ }^{1}$, Antonio Morales ${ }^{1}$, Daniel O. Palenzuela ${ }^{2}$, Liliana Basabe ${ }^{1}$, Fidel \\ Herrera $^{1}$, Osmany Rodrigo ${ }^{1}$, Janet Velázquez ${ }^{3}$, Soraya Piloto ${ }^{4}$, Mario P. Estrada ${ }^{1 *}$ and Rebeca Martínez ${ }^{1 *}$ \\ ${ }^{1}$ Metabolic Modifiers for Aquaculture, Agricultural Biotechnology Department, Center for Genetic Engineering and Biotechnology, Havana, Cuba \\ ${ }^{2}$ Pharmacogenomics Project, Systems Biology Department, Center for Genetic Engineering and Biotechnology, Havana, Cuba \\ ${ }^{3}$ Veterinary Immunology Project, Agricultural Biotechnology Department, CIGB, Havana, Cuba \\ ${ }^{4}$ Microbiology Laboratory, Quality Control Department, Center for Genetic Engineering and Biotechnology, Havana, Cuba
}

${ }^{*}$ Corresponding authors: Dr. Mario P. Estrada, Metabolic Modifiers for Aquaculture, Agricultural Biotechnology Department, Center for Genetic Engineering and Biotechnology, Havana, Cuba; Email: mario.pablo@cigb.edu.cu

Dr. Rebeca Martínez, Metabolic Modifiers for Aquaculture, Agricultural Biotechnology Department, Center for Genetic Engineering and Biotechnology, Havana, Cuba; Email: rebeca.martinez@cigb.edu.cu

Received: December 23, 2021; Accepted: December 27, 2021; Published: January 03, 2022

\section{Introduction}

Edwardsiella tarda is one of the most significant bacterial pathogens to fish aquaculture. This Gram-negative, intracellular bacterium is the causal agent of the "edwardsiellosis" which cause generalized septicemia and lesions on internal organs. It has been reported worldwide in economically important fish species, including Japanese eel (Anguilla japonica), red sea bream (Pagrus major), yellowtail (Seriola quinqueradiata), channel catfish (Ictalurus punctatus), turbot (Scophthalmus maximus) and tilapia (Oreochromis sp.) [1,2]. This infection leads to enormous economic losses in cultured seawater and freshwater fish [1].

Different strategies have been attempted to treat and prevent E. tarda infections, including antibiotics and chemicals. However, overuse or abuse of these can result in the selection and development of drug resistant pathogens [3,4]. As a promising alternative, immunostimulants may represent a safe and effective treatment to enhance an antimicrobial response for preventing fish infection by a wide range of pathogens.

Synthetic growth hormone (GH) secretagogues (GHSs) consist of a family of ligands, initially termed GH-releasing peptides (GHRPs) [5] which are recognized by the GHS receptor (GHS-R). GHS-R is expressed predominantly in the brain and pituitary gland, and in immune system cells from mammals and fish, suggesting a relation between ligands for these receptors and the immune system [6]. Growth Hormone-Releasing Peptide 6 (GHRP-6) is a six amino acid synthetic peptide with demonstrated stimulatory effects on innate and adaptive immune system in teleost fish $[7,8]$. The aim of this study was to assess the antimicrobial effects of GHRP- 6 against bacterial infection in tilapia, as well as to measure gene expression of some immune-related genes before and after E. tarda infection.

\section{Materials and Methods}

\section{Fish and Peptide Source}

Juvenile tilapias (Oreochromis niloticus, male, $\sim 100 \mathrm{~g}$ ) were obtained from the Aquaculture Research Station at the Center for the Genetic Engineering and Biotechnology (CIGB), Havana, Cuba. Fish were kept alive in aerated freshwater in $120 \mathrm{~L}$ tanks under a $12 \mathrm{~h}$ light: $12 \mathrm{~h}$ dark photoperiod. They were fed commercial dry diet for fish (CENPALAB, Habana, Cuba). Water temperature was maintained at $26-28^{\circ} \mathrm{C}$. Fish were acclimated for one week before each experiment. All animal experiments were previously approved by the Ethics Committee of the Center for Genetic Engineering and Biotechnology, Havana, Cuba. The described work has been carried out in accordance with EU Directive 2010/63/EU for animal experiments.

GHRP-6 (His-(D-Trp)-Ala-Trp-(D-Phe)-Lys-NH2, MW = 872.44 Da) with a purity $>99 \%$ was provided by Sigma-Aldrich, USA.

\section{Fish Treatment with GHRP-6}

Fish (26 tilapias per group) were injected by intraperitoneal route (i.p) during 7 days. One group of tilapias received GHRP-6 (0.2 $\mu \mathrm{g} /$ body weight (bwg)) in a total volume of $100 \mu \mathrm{L}$ of PBS. The Control group was injected with the same volume of PBS. The dose employed for GHRP-6 was chosen based in previous experiments performed in the laboratory [9]. Spleen samples $(n=6)$ were taken at 24 and 48 hours after the last injection. Tissue samples were stored in Ambion RNAlater (AppliedBiosystems, USA) at $-20^{\circ} \mathrm{C}$ until use for RNA isolation.

Also, at 48 hours after the last peptide injection, a challenge was performed using an E. tarda strain by immersion bath as previously described by [10], with minor adjustments. Edwardsiella tarda strain 
was obtained from glycerol stock cultures stored at $-80^{\circ} \mathrm{C}$. Briefly, Nile tilapia juveniles ( $\mathrm{n}=13$ per group) were exposed to $108 \mathrm{CFU} / \mathrm{mL}$ of E. tarda (diluted in sterile PBS) by immersion bath during $1 \mathrm{~h}$ in a total volume of $40 \mathrm{~L}$ with aeration. After immersion bath, both groups were moved to $250 \mathrm{~L}$ aerated freshwater tanks in an isolated water flow system and kept in those conditions until sampling of gills and spleen (8 fish per group). The rest of the animals were daily checked until day 5th day when mortality started to occur. Two additional tanks with fish ( $n=7$ per group: PBS and GHRP-6) were used as non-challenge controls of mortality. After the challenge concluded, waste water was treated with chlorine to avoid the releasing of live bacteria.

Spleen was sampled at 24 and 48 hours after challenge (hac) for gene expression analysis, as described above. To evaluate the antimicrobial effects of GHRP-6 on gills, samples were taken at 48 hours after the challenge (hac), under aseptic conditions and washed in $1 \mathrm{~mL}$ of $0.9 \% \mathrm{NaCl}$. Afterwards, this wash was serially diluted in sterile PBS, plated in tryptic soy agar (TSA) (Merck) and grown overnight at $37^{\circ} \mathrm{C}$. The identity of the colonies grown in specific culture medium was confirmed by an API20E test (Biomérieux) and Gram staining.

\section{Gene Expression Analysis}

Tissue samples were processed on a Tissue Lyser unit (Qiagen, Hilden, Germany), extracting total RNA with RNeasy ${ }^{\oplus}$ Plus (QIAGEN $\mathrm{GmbH}$, Germany) using the Quiacube platform. RNA purity and yield were determined using a NanoDrop Spectro-photometer (NanoDrop Technologies, USA). First-strand complementary DNA (cDNA) was synthesized from $1 \mu \mathrm{g}$ total RNA using Superscript III First-Strand Synthesis Supermix for RT-PCR (Invitrogen Technologies, Carlsbad, California, USA) following fabricant's instructions.

Transcripts levels in the sampled organs were assessed by qPCR analysis. Gene's sequences were obtained from the US National Center for Biotechnology Information database (NCBI). Specific primers were designed, using the web application Primer3 [11]. Each experimental sample was run in triplicate on 96-well plates and APCR reactions were completed on the LightCycler ${ }^{\circ} 480$ II (Roche). All PCR reactions were of $20 \mu \mathrm{L}$ volume and contained: $10 \mu \mathrm{L}$ of LightCycler ${ }^{\circledR} 480$ SYBR Green I Master 2x (Roche, Germany), $300 \mathrm{nM}$ each primer (10 pmol/ $\mu \mathrm{L}$ ) and $4 \mu \mathrm{L}$ of cDNA (50 ng/ $\mu \mathrm{L}$ diluted 1:25 in RNase free water). For each plate, triplicate wells of a calibrator and RNA only control were also present. The program used for all qPCR reactions was as follows: pre-incubation at $95^{\circ} \mathrm{C}$ for $5 \mathrm{~min}$ followed by 50 cycles of denaturation at $95^{\circ} \mathrm{C}$ for $15 \mathrm{sec}$, annealing at $60^{\circ} \mathrm{C}$ for $30 \mathrm{~s}$ and extension at $72^{\circ} \mathrm{C}$ for $30 \mathrm{~s}$. A melting curve was completed for every run from 72 to $95^{\circ} \mathrm{C}$ with a read every $5 \mathrm{~s}$. Product specificity was determined through single PCR melting peaks. All qPCR data was analyzed using REST 2009 v2.0.13 [12]. Differences were expressed as fold changes. Gene expression was normalized to the references genes EF- $1 \alpha$ and $\beta$-actin.

\section{Statistical Analysis}

The effects of GHRP- 6 on the number of CFU in gills, was assessed using GraphPad Prism version 6.0 for Windows (GraphPad Software, San Diego, CA). The normal distribution of data was analyzed with D'Agostino Pearson's test and the variance homogeneity with Bartlett's test. A Student's t parametric test was performed as data followed normal distribution for comparisons in each time point. For qPCR analysis, reactions efficiency was calculated using LinReg software and data were analyzed using REST 2009 software v2.0.13 [12,13]. This software calculates the relative expression to a control condition after normalize with the efficiency of the selected references genes. Differences were expressed as fold changes relative to Control group. A significance level of 0.05 was used for all analyses.

\section{Results}

After the last peptide injection with GHRP-6, the transcripts levels of IL- $1 \beta$ relative to Control group were up-regulated in spleen both at $24(2.37 \pm 0.58)$ and $48(2.27 \pm 1.64)$ hours. Also, Oreochromicin III was significantly up-regulated at 48 hours after treatment (5.99 \pm 3.48 ). However, no significant differences were observed for Oreochromicins I and II and Granzyme transcripts (Figure 1).

Once confirmed the positive modulation of a pro-inflammatory cytokine and an antimicrobial peptide in spleen, we evaluated the antimicrobial effect promoted by GHRP- 6 after a challenge trial with E. tarda. With this aim, fish were challenged 48 hours after the peptide treatment with an E. tarda strain. Spleen samples were collected at 24 and 48 hours after challenge, while gills washes and were taken at 48 hours.

GHRP-6 treatment exerts a differential modulation over Oreochromicins, Granzyme and IL-1 $\beta$ mRNA expression profiles in spleen after E. tarda infection. Oreochromicin I was up-regulated $(7.49 \pm 3.32)$ at 48 hours, while, Oreochromicins II and III were downregulated at 24 hours $(0.12 \pm 0.17$ and $0.09 \pm 0.07$, respectively). On the other hand, IL- $1 \beta$ was statistically down-regulated $(0.067 \pm 0.002)$ at 48 hours (Figure 2).

In gills washes, there were statistically significant lower CFU/mL of bacteria in group treated with GHRP-6 (6.8 x $104 \pm 8.6 \times 103 \mathrm{CFU} /$ $\mathrm{mL})$ compared to the Control group $(3.9 \times 105 \pm 6.4 \times 104 \mathrm{CFU} / \mathrm{mL})$

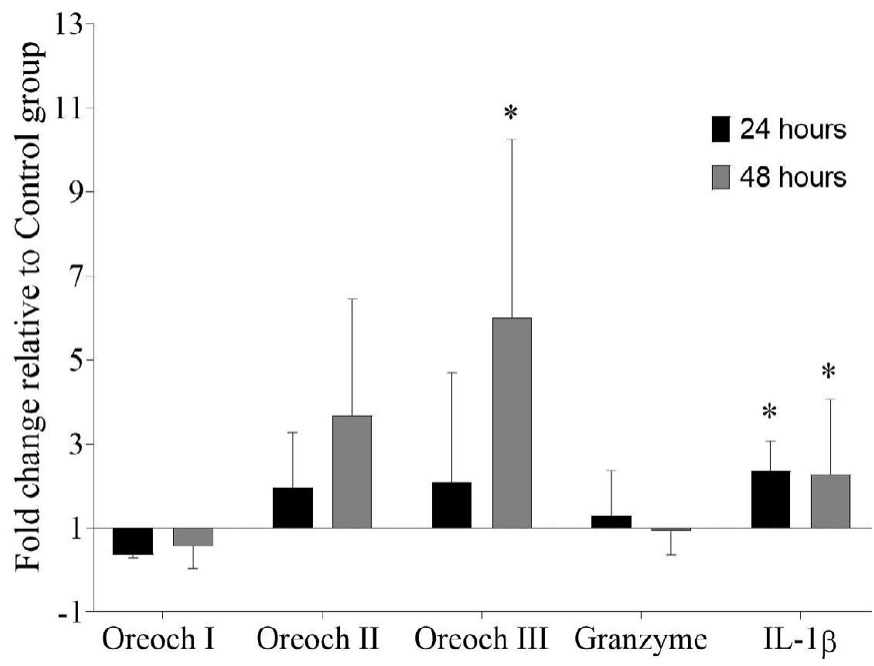

Figure 1: Gene expression analysis in spleen of tilapia (Oreochromis sp.) after treatment with GHRP- 6 during seven consecutive days by i.p injection. Samples were taken at 24 and 48 hours after the last peptide injection. Fold change (FC) with respect to Control group were calculated by REST 2009 (FC>1 up-regulated; FC $<1$ down-regulated) and were expressed as mean \pm SD $(n=6)$. The asterisks indicate statistically significant differences relative to Control group, ${ }^{\star}(p<0.05)$. 
(Figure 3). We observed clinical signs of the disease in some animals of the Control group such as loss of pigmentation and petechial hemorrhage in fin and skin, aspects reviewed by [1] as evidence of the infection. We started to observed mortality in Control group of infected fish since the 5th day, being 4/7 in Control group and 0/7 in GHRP-6 treated group.

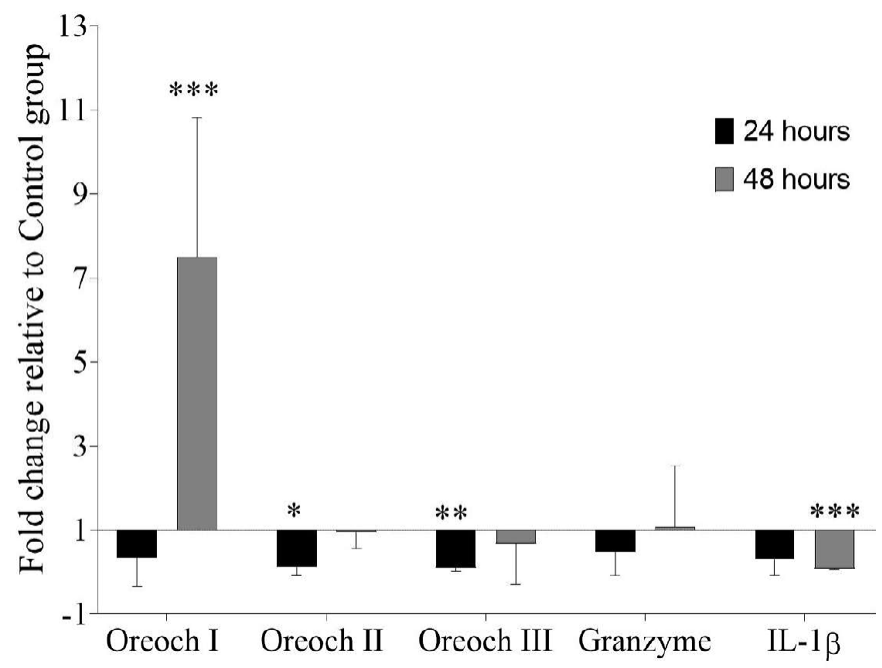

Figure 2: Gene expression analysis in spleen of tilapia (Oreochromis sp.) after treatment with GHRP-6 (during 7 consecutive days by i.p injection) and challenge with an Edwardsiella tarda strain. Twenty-four and 48 hours after the last peptide injection, fish from Control and GHRP-6 treated groups (13 fish per group) were exposed for one hour to $1 \times 10^{8} \mathrm{CFU} / \mathrm{mL}$ of $E$. tarda by immersion bath. Gene transcription was analyzed by qPCR in spleen sampled at 24 and $48 \mathrm{~h}$ after challenge. Fold change (FC) with respect to Control group were calculated by REST 2009 (FC $>1$ up-regulated; FC $<1$ down-regulated) and were expressed as mean $\pm \mathrm{SD}(\mathrm{n}=8)$. The asterisks indicate statistically significant differences relative to Control group, ${ }^{*}(p<0.05),{ }^{* *}(p<0.01)$ and ${ }^{* * *}(p<0.001)$

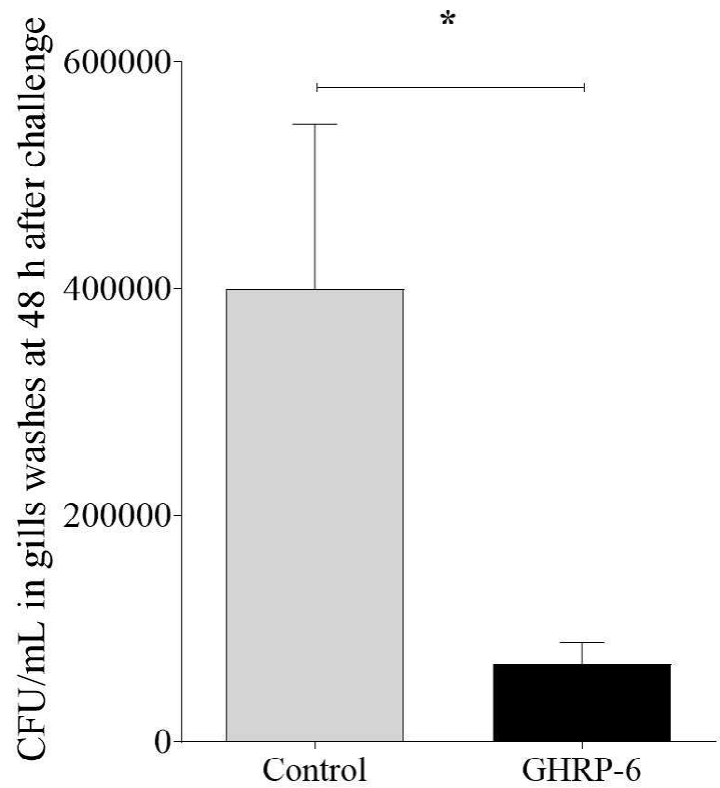

Figure 3: Gills' bacterial load in Control and GHRP-6 treated groups after treatment with GHRP-6 (during 7 consecutive days by i.p injection) and challenge with an Edwardsiella tarda strain. Forty-eight hours after the last peptide injection, fish from Control and GHRP-6 treated groups (13 fish per group) were exposed for one hour to $1 \times 10^{8} \mathrm{CFU} /$ $\mathrm{mL}$ of $E$. tarda by immersion bath. Total number of CFU/mL in gills washes were counted at $48 \mathrm{~h}$ after challenge. Data represent the mean $\pm \mathrm{SD}(\mathrm{n}=8)$ of three independent experiments. The analysis of data was performed using a Student's $t$ test. The asterisks represent statistically significant differences between groups, ${ }^{*}(p<0.05)$.

\section{Discussion}

Edwardsiella tarda is a Gram-negative intracellular pathogen which causes enormous economic losses in cultured seawater and freshwater fish [14]. Infection by E. tarda may produce severe lesions in internal organs such as spleen [15-17]. Gills constitutes one of the entry routes of $E$. tarda infections in fish [18], thus, the use of immunostimulants with antimicrobial effects for preventing infestations could be promising.

Previously, it has been demonstrated that GHRP-6 is a growth hormone secretagogue that improve different innate and adaptive immune system parameters in aquatic organisms [7,8,19]. More recently, we provided new evidence of a direct link between GHRP6 treatment and enhanced antimicrobial peptides transcription in tilapia [20]. In this study we shed light over the effect of this peptide as stimulator of the antimicrobial immune response in tilapia with and without the presence of a challenge with E. tarda.

Spleen constitutes one of the major lymphoid tissues in fish and also is affected by the infection with bacterial pathogens, such as $E$. tarda [21]. GHRP-6 statistically up-regulated the mRNA levels of IL-1 $\beta$ in tilapia spleen. Our results are in agreement with previous studies where IL-1 $\beta$ was up-regulated after the administration of immunostimulants $[22,23]$.This cytokine is a critical mediator of the inflammatory response against microbial invasion and can stimulate the immune response by activating lymphocytes or by inducing the release of other cytokines capable of triggering macrophages, NK cells and lymphocytes (Yuan et al., 2008; [18,24]. Also, Oreochromicin III was up-regulated after the treatment with the GHS. Previous studies have demonstrated that this antimicrobial peptide has immunomodulatory effect in mammals. Oreoch III stimulated the release of IFN- $\gamma$ from mice splenocytes [25].

In the current study, Oreochromicins I, II and III were differentially regulated by GHRP-6 in spleen after the challenge with $E$. tarda. Therefore, Oreochromicins could be involved in the elimination of this pathogen in tilapia spleen and other tissues. These antimicrobial peptides belong to the piscidin-like family and are expressed in different cell types such as neutrophils, granular eosinophils, monocytes and macrophages [26]. [27] demonstrated strong antimicrobial activity of Oreochromicin II against $E$. tarda in vitro. Recent studies revealed that GHRP-6 stimulates the antimicrobial immune response against Pseudomonas aeruginosa in tilapia and up-regulated the transcription of Oreochromicins as well in the presence of this pathogen [20].

Our results revealed that the treatment with GHRP-6 statistically decreased the bacterial load of E. tarda in gills washes 48 hours after the challenge as we observed a significant up-regulation of the mRNA levels of Oreochromicin I in spleen. Fish's gills possess different cells populations and a mucus layer associated to it, which contains different antimicrobial molecules that contribute to the bacterial clearance $[28,29]$. The obtained results suggested that GHRP- 6 may stimulate the antimicrobial response which limits the growth of the bacteria in gills, and thus could restrict the bacterial infection. Previous reports have shown that AMPs can protect against infections by E. tarda in fish [30]. Further studies will be conducted in order to gain knowledge 
at the histological level. In addition, after the challenge, we observed a down-regulation of IL-1 $\beta$. Previous studies have demonstrated that when the expression of this cytokine decreases significantly at 48 hours, it is possible that this has increased within a few hours of completing the challenge. For example, [31], showed that in a challenge with Aeromonas salmonicida by intraperitoneal injection, IL-1 $\beta$ levels in spleen were up-regulated at 2 and 6 hours after the infection, but at 24 hours did not showed significant differences. Moreover, in a challenge carried out with $E$. tarda by intramuscular injection, an increase in IL$1 \beta$ expression was obtained at 6 and 24 hours, in animals previously immunized with the flagellar protein FlgD by intramuscular injection [32-34].

The results of this trial suggest that the induction of IL- $1 \beta$ could be transient and that other effector components of innate immunity are participating in the protection of the organism. Various authors showed that when the expression of this cytokine decreases significantly at 48 hours, it is possible that this has increased within a few hours of completing the challenge.

In summary, our results suggested novel roles of GHRP-6 in tilapia as possible immunostimulant, which is able to promote the antimicrobial activity against some Gram-negative intracellular bacterial infections, such as E. tarda. Currently we are planning to evaluate the protective effect of this GHS at the histological level when administered in the presence of pathological bacteria such as E. tarda. Also, we are developing an oral formulation in order to evaluate its immunostimulant effects in long term experiments as part of the diet and its effects on guts bacterial load after a bacterial challenge. These studies will allow us to gain a deeper knowledge about the molecular basis of GHRP-6 mechanism in relation with antibacterial response in fish for its potential application in aquaculture.

\section{Author Contributions}

LH performed majority of experiments, contributed to experimental design, wrote the first draft and reviewed the final version of the manuscript. HC, ANR, DP, AM, LB, FH, OR, SP contributed with the development of the experiments. JV contributed with the development of the experiments and reviewed the final version of the manuscript. ME, contributed to experimental design and reviewed the final version of the manuscript. RM contributed to experimental design, wrote the first draft of the manuscript and reviewed the final version of the manuscript.

\section{Data Availability}

The raw data supporting the conclusions of this manuscript will be made available by the authors, without undue reservation, to any qualified researcher.

\section{Keywords: GHRP-6, Antimicrobial activity, Edwardsiella tarda, Tilapia}

\section{References}

1. Park Bin S, Aoki T, Jung TS (2012) Pathogenesis of and strategies for preventing Edwardsiella tarda infection in fish. Veterinary Research 43: 1-11.

2. Baba E, Acar Ü, Öntaș C, Kesbiç OS, Yllmaz S (2016) Evaluation of Citrus limon peels essential oil on growth performance, immune response of Mozambique tilapia Oreochromis mossambicus challenged with Edwardsiella tarda. Aquaculture 465: 13-18.
3. Cha YJ, Lee CR., Kwon JY, Kang YJ (2017) Protective effects of CpG-ODN 2007 administration against Edwardsiella tarda infection in olive flounder (Paralichthys olivaceus). Fish and Shellfish Immunology 68: 327-331. [crossref]

4. Na-Phatthalung P, Teles M, Voravuthikunchai SP, Tort L, Fierro-Castro C (2018) Immune-related gene expression and physiological responses in rainbow trout (Oncorhynchus mykiss) after intraperitoneal administration of Rhodomyrtus tomentosa leaf extract: A potent phytoimmunostimulant. Fish and Shellfish Immunology 77: 429-437. [crossref]

5. Momany FA, Bowers CY, Reynolds GA, Chang D, Hong A, et al. (1981) Design, Synthesis, and Biological Activity of Peptides which Release Growth Hormone in Vitro. Endocrinology 108: 31-39.

6. Hattori N (2009) Growth Hormone \& IGF Research Expression, regulation and biological actions of growth hormone ( $\mathrm{GH}$ ) and ghrelin in the immune system. Growth Hormone \& IGF Research 19: 187-197. [crossref]

7. Martinez R, Carpio Y, Morales A, Lugo JM, Herrera F, et al. (2016a) Oral administration of the growth hormone secretagogue-6 (GHRP-6) enhances growth and non-specific immune responses in tilapia (Oreochromis sp.). Aquaculture 452: 304-310.

8. Martínez R, Hernández L, Gil L, Carpio Y, Morales A, et al. (2017a) Growth hormone releasing peptide- 6 enhanced antibody titers against subunit antigens in mice $(\mathrm{BALB} / \mathrm{c})$, tilapia (Oreochromis niloticus) and African catfish (Clarias gariepinus). Vaccine 35: 5722-5728. [crossref]

9. Martinez R, Núñez de Villavicencio-Díaz T, Sánchez A, Noda J, Gil L, et al. (2016b) Comparative proteomics analysis of growth hormone secretagogue A233 treatment effect in J774A.2 murine macrophages cells. Biochem Biophys Rep 5: 379-387. [crossref]

10. Velázquez J, Acosta J, Herrera N, Morales A, González O, et al. (2017) Novel IFN $\gamma$ homologue identified in Nile tilapia (Oreochromis niloticus) links with immune response in gills under different stimuli. Fish and Shellfish Immunology 71: 275-285. [crossref]

11. Rozen S, Skaletsky H (2000) Primer3. Methods Mol Biol 132: 365-386.

12. Pfaffl MW, Horgan GW, Dempfle L (2002) Relative expression software tool (REST(C)) for group-wise comparison and statistical analysis of relative expression results in real-time PCR. Nucleic Acids Research 30: 36. [crossref]

13. Camacho-Rodiguez H, Guillén-Pérez IA, Roca-Campaña J, Baldomero-Hernández JE, Tuero-Iglesias, et al. (2018) Heberprot-P's Effect on Gene Expression in Healing Diabetic Foot Ulcers. MEDICC Review 20: 10-14. [crossref]

14. Mohanty BR, Sahoo PK (2010) Immune responses and expression profiles of some immune-related genes in Indian major carp, Labeo rohita to Edwardsiella tarda infection. Fish and Shellfish Immunology 28: 613-621. [crossref]

15. Mohanty BR, Sahoo PK (2007) Edwardsiellosis in fish: a brief review. Journal of Biosciences 32: 1331-1344. [crossref]

16. Zhou Z, Sun L (2016) Edwardsiella tarda-Induced Inhibition of Apoptosis: A Strategy for Intracellular Survival. Frontiers in Cellular and Infection Microbiology 6: 76. [crossref]

17. Lee W, Ahn G, Young J, Min S, Kang N, et al. (2016) A prebiotic effect of Ecklonia cava on the growth and mortality of olive flounder infected with pathogenic bacteria. Fish and Shellfish Immunology 51: 313-320. [crossref]

18. Pressley ME, Phelan PE, Eckhard Witten P, Mellon MT, Kim CH (2005) Pathogenesis and inflammatory response to Edwardsiella tarda infection in the zebrafish. Developmental and Comparative Immunology 29: 501-513. [crossref]

19. Martínez R, Carpio Y, Arenal A, Lugo JM, Morales R, et al. (2017b) Significant improvement of shrimp growth performance by growth hormone-releasing peptide-6 immersion treatments. Aquaculture Research 48: 4632-4645.

20. Hernández L, Camacho H, Nuñez-Robainas A, Palenzuela DO, Morales A, et al. (2021) Growth hormone secretagogue peptide- 6 enhances oreochromicins transcription and antimicrobial activity in tilapia (Oreochromis sp.). Fish and Shellish Immunology 119: 508-515. [crossref]

21. Velázquez J, Acosta J, Lugo JM, Reyes E, Herrera F, et al. (2018) Discovery of immunoglobulin $\mathrm{T}$ in Nile tilapia (Oreochromis niloticus): A potential molecular marker to understand mucosal immunity in this species. Developmental and Comparative Immunology 88: 124-136. [crossref] 
22. Nootash S, Sheikhzadeh N, Baradaran B, Oushani AK, Maleki Moghadam MR, et al. (2013) Green tea (Camellia sinensis) administration induces expression of immune relevant genes and biochemical parameters in rainbow trout (Oncorhynchus mykiss). Fish and Shellfish Immunology 35: 1916-1923. [crossref]

23. Huang X, Hu B, Yang X, Gong L, Tan J, et al. (2019) The putative mature peptide of piscidin-1 modulates global transcriptional profile and proliferation of splenic lymphocytes in orange-spotted grouper (Epinephelus coioides). Fish and Shellfish Immunology 86: 1035-1043. [crossref]

24. Mehrabi Z, Firouzbakhsh F, Rahimi-Mianji G, Paknejad H (2019) Immunostimulatory effect of Aloe vera (Aloe barbadensis) on non-specific immune response, immune gene expression, and experimental challenge with Saprolegnia parasitica in rainbow trout (Oncorhynchus mykiss). Aquaculture 503: 330-338.

25. Acosta J, Carpio Y, Valdés I, Velázquez J, Zamora Y, et al. (2014) Co-administration of tilapia alpha-helical antimicrobial peptides with subunit antigens boost immunogenicity in mice and tilapia (Oreochromis niloticus). Vaccine 32(2): 223229. [crossref]

26. Valero Y, Saraiva-fraga M, Guardiola FA (2018) Antimicrobial peptides from fish: beyond the fight against pathogens. Reviews in Aquaculture 12: 1-30.

27. Acosta J, Montero V, Carpio Y, Velázquez J, Garay HE, et al. (2013) Cloning and functional characterization of three novel antimicrobial peptides from tilapia (Oreochromis niloticus). Aquaculture 372-375: 9-18.
28. Koppang EO, Kvellestad A, Fischer U (2015) Mucosal Health in Aquaculture Fish mucosal immunity: gill. In Mucosal Health in Aquaculture. Elsevier.

29. Cabillon N, Lazado C (2019) Mucosal Barrier Functions of Fish under Changing Environmental Conditions. Fishes 4: 2.

30. Liang Y, Guan R, Huang W, Xu T (2011) Isolation and identification of a novel inducible antibacterial peptide from the skin mucus of Japanese Eel, Anguilla japonica. Protein Journal 30: 413-421. [crossref]

31. Feng CY, Johnson SC, Hori TS, Rise M, Hall JR, et al. (2009) Identification and analysis of differentially expressed genes in immune tissues of Atlantic cod stimulated with formalin-killed, atypical Aeromonas salmonicida. Physiol. Genomics 37: 149163. [crossref]

32. Zhang M, Wu H, Li X, Yang M, Chen T, et al. (2012) Edwardsiella tarda flagellar protein FlgD: A protective immunogen against edwardsiellosis. Vaccine 30: 38493856. [crossref]

33. Costa AA, Leef MJ, Bridle AR, Carson J, Nowak BF (2011) Effect of vaccination against yersiniosis on the relative percent survival, bactericidal and lysozyme response of Atlantic salmon, Salmo salar. Aquaculture 315: 201-206.

34. Xu T, Zhang XH (2014) Edwardsiella tarda: An intriguing problem in aquaculture. Aquaculture 431: 129-135.

\section{Citation:}

Hernández L, Camacho H, Nuñez-Robainas A, Morales A, Palenzuela DO, et al. (2021) Growth Hormone Secretagogue Peptide-6 Modulates Antimicrobial Activities in Tilapia (Oreochromis sp.) Challenged with Edwardsiella tarda. Aquac Fish Stud Volume 3(5): 1-5. 